Article

\title{
Engaging with Hard-To-Reach Clients: Towards the Last Resort Response by Welfare Workers
}

\author{
Sirpa Saario ${ }^{1, *}$, Christopher Hall ${ }^{2}$ and Doris Lydahl ${ }^{3}$ \\ ${ }^{1}$ Faculty of Social Sciences, Tampere University, Finland; E-Mail: sirpa.saario@tuni.fi \\ 2 Social Work and Social Care, University of Sussex, UK; E-Mail: ch550@sussex.ac.uk \\ ${ }^{3}$ Department of Sociology and Work Science, University of Gothenburg, Sweden; E-Mail: doris.lydahl@gu.se \\ * Corresponding author
}

Submitted: 30 March 2021 | Accepted: 31 May 2021| Published: 26 August 2021

\begin{abstract}
Client non-cooperation is a widely recognised problem in welfare services. Being 'hard-to-reach' is considered a risk especially for the most vulnerable clients, for example in terms of increased homelessness. Such clients pose challenges to social inclusion, and services make some allowances to achieve engagement. However, even a minimum level of cooperation is required from hard-to-reach clients. In the context of home visiting, we study welfare workers' efforts to engage with clients who continuously avoid contact. We examine three services in Finland, England, and Sweden that provide floating support to clients in their own accommodation. Utilising Robert Emerson's idea of 'the last resort,' we analyse how workers justify their decisions to continue or terminate the support with the hard-to-reach. The data consist of team meeting recordings and home visit observations. We aim to demonstrate that justifications deployed to make the decision to end the home visiting service or tighten control, draw on 'last resort responses.' We identify three types of justifications: retrospective summaries on past failures to reach the client, intensifying remedial actions to engage clients, and characterisations of clients as uncooperative. While such justifications can be seen to draw on shared ethics, they have different ethical implications.
\end{abstract}

\section{Keywords}

floating support; hard-to-reach clients; home visiting; last resort; social work; welfare workers

Issue

This article is part of the issue "Home- and Community-Based Work at the Margins of Welfare: Balancing between Disciplinary, Participatory and Caring Approaches" edited by Kirsi Juhila (Tampere University, Finland), Cecilia Hansen Löfstrand (University of Gothenburg, Sweden) and Johanna Ranta (Tampere University, Finland).

(C) 2021 by the authors; licensee Cogitatio (Lisbon, Portugal). This article is licensed under a Creative Commons Attribution 4.0 International License (CC BY).

\section{Introduction}

Hard-to-reach clients, also termed as 'service refusers' (Beresford, 2005) or 'care avoiders' (Cortis, 2012), are common in welfare services (Froonjian \& Garnett, 2013). According to Cortis (2012, p. 352), hard-to-reach clients refer to "those people eligible for assistance but who, for a range of reasons, do not usually take up the help available" or are "difficult for service providers to engage." Within social care, the notion of hard-to-reach client is well recognised. In the 1950s, Lindenberg (1958) and Tinker (1959) described the challenging relations between the services and hard-to-reach clients in a way that today remains relevant: A fundamental paradox lies at the heart of commitment and needs. In other words, if these clients would commit to care without problems, would they need help in the first place? The hard-toreach clients might need help exactly because they are hard-to-reach and thus face risks associated with isolation. Reaching elusive clients is a challenging task especially in the current community care where clients spend less time in long-term institutional care (Emmel et al., 2007). From the perspective of social inclusion, home visiting hard-to-reach clients can be compared to 'outreach 
work' with clients that cannot effectively be reached by existing services (Andersson, 2013; Grymonprez et al., 2017). To identify this group, policy makers have constructed a category of hard-to-reach clients "to organise and encode members of particular populations on the basis of their marginalisation from welfare services" (Cortis, 2012, p. 352). They become transformed "into entities that the organisation can recognise and process" (Hjörne et al., 2010, p. 305).

The impetus for this article stems from examining data collected from services offering floating support for vulnerable clients in three national contexts: Finland, Sweden, and England. We noticed that despite the different context, workers in each service spend considerable time just contacting and motivating their clients in the first place. This article presents a variety of workers' efforts to deal with non-cooperating clients and unrealised home visits. Not being able to meet clients challenges floating support workers' key mission to support clients via visiting the home and engaging in face-to-face interaction in their personal environment (Juhila et al., 2021). This article studies what happens when this mission continuously fails: How do workers justify their decisions to continue or terminate home visits with the hard-to-reach? Such justifications are analysed as 'last resort responses' (Emerson, 1981), or stages towards the last resort response when the support does not proceed as planned.

\section{Last Resorts: Literature and a Tool for Analysis}

Empirical studies drawing on last resorts can be examined in terms of three approaches: some examine 'last resort services,' others 'last resort procedures,' or 'last resort responses.' All have a bearing on this article but the last one forms the basis of our analysis.

Last resort services refer to those services which are at the end of the line in terms of managing particularly troublesome clients. Emerson (1981, p. 1) refers to psychiatric hospitals or juvenile incarceration as remedies which are available to be used but which "are considered likely to compromise or defeat the very ends they were intended to achieve." Harnett and Jönson (2020, p. 1) describe 'wet eldercare,' "where goals of abstinence are abandoned in favour of goals of increased wellbeing for older people with long term substance disorder." The justification is that such clients have tried and failed all other forms of treatment, so they are provided with accommodation, care, and a 'decent life,' whilst their substance abuse is tolerated within certain limits. A similar characterisation is made of methadone maintenance programmes by Järvinen and Miller (2010, p. 805). The programmes are usually provided for people with a long history of drug addiction when all other interventions have failed. Concern is addressed towards these services resulting in participants seeing themselves as "fundamentally different from other people and unreachable by more therapeutically oriented measures" (Järvinen \& Miller, p. 820).
Last resort procedures identify steps that professionals take to assess and monitor the decline in clients' compliance with the rules of the service, for example, if they are attending designated meetings and carrying out agreed tasks. As clients begin to miss such targets, the professional may make allowances at first and 'give them the benefit of the doubt.' Heimer and Staffen (1995, p. 649) studied how hospital staff managed the lack of support by parents for their sick infants. Effort was made to maintain positive assessments of the parents, what they call 'reintegrative social control': For example, mothers who did not visit their infants were telephoned. If inappropriate behaviour was not repeated, staff members concluded that the parents were learning. But if parents were recalcitrant, non-compliance was monitored and "only after numerous attempts to reshape parents' behaviour is the state's child welfare agency contacted" (Heimer \& Staffen, 1995, p. 650). The move from the characterisation of parents as supporting their infant to those who are not able to care for them requires a major realignment, and only takes place in extreme circumstances. Reintegrative social control importantly lays out steps taken to engage with the client prior to the move to last resorts, similar to the remedial actions described by Emerson (1981). Formal procedures may be deployed to facilitate monitoring of the move to last resort responses (Miller \& Holstein, 1995). Having moved through various procedures, the formulation of last resort is finally mobilised.

Instead of considering last resorts as appertaining to characteristics of services or procedures, in our analysis we return to Emerson's statement of them as 'social control responses' (Emerson, 1981, p. 1). In this way, many social institutions are likely to deploy last resort responses, when they attempt to manage difficult clients. Last resort responses are preceded by various justifications by the workers. According to Emerson (1981), the last resort response is always preceded by first resort responses. The support process (e.g., a series of home visits) has a beginning and a middle phase that can be described as what Emerson calls the 'normal remedies' as the first responses. In cases managed over time "responses are properly invoked in a specified order, with those regarded as milder preceding the more severe" (Emerson, 1981, p. 6). In these cases, first-resort decisions are typically presented as what should or ought to be done.

In the last resort phase, the inappropriateness of normal remedies is established by constructing a history of how prior remedies had been appropriately deployed but were demonstrably unsuccessful. No other course of action is viable but the last-resort sanction (Emerson, 1981, p. 6). To invoke a last-resort sanction successfully, it must be shown that normal remedial actions either are specifically inappropriate or have been tried but have failed to contain the trouble. In contrast to 'normal remedies,' last-resort decisions are typically framed in an idiom of necessity. With the last-resort decision, "there is no alternative" (Emerson, 1981, p. 5). 
Importantly, last resorts responses provide a justificatory decision logic that Emerson (1981, p. 19) describes in the following way:

When control agents contend that they use certain extreme sanctions "only as a last resort," they are offering not so much a factual description of their own procedures as an account... demonstrating (or at least asserting) the rational, necessary character of those decisions.

This view is useful in our analysis utilising interactional data with workers' talk and action. We approach last resort responses as a feature of organisational interactions in which formulations of clients' non-cooperation are constructed and negotiated. Last resort responses make particular use of contrasts between preferred and unpreferred versions of clients (first and last resort responses) and tend towards extreme notions of character and behaviour.

\section{Floating Support Settings}

In line with the premises of community care, the services we examine aim to facilitate vulnerable clients' meaningful lives within their local communities by supporting them in their own accommodation. Each service employs welfare workers with different vocational backgrounds, such as practical nurses, substance abuse workers and home care workers. We study the following three floating support settings situated in three countries.

The Finnish service is a non-governmental organisation operating under an outsourcing contract with the municipality. Clients' tenancy is tied to floating support, so there is an organisational expectation for the clients to cooperate by participating in regular home visits, as well as workers achieving a certain amount of home visits per month. In this sense clients have obligations to be present at home visits. The apartments are owned by the municipality. Tenancy contracts are signed between the client and the commissioners that administrate the tenancies. The target group is clients with co-occurring mental health and substance abuse problems. The workers can to some extent influence the clientele by communicating their opinions on the suitability of a client to their service for the municipal decision-makers, i.e., the commissioners.

The English service is also a non-governmental organisation operating under an outsourcing contract with the municipality. However, tenancy is separate from support as the clients mostly live in their own or rental apartments with no ties to the support service. In this sense the possible ending of floating support does not have such significant consequences for clients as they can remain in their apartment. The service has a generic orientation and is intended for people with a wide range of mental health problems. Some clients with significant challenges have a care coordinator from the community mental health team who is responsible for managing the client's overall services.

Unlike the two other previous services, the Swedish service is run by the municipality. The service is based on the Housing First model (Hansen Löfstrand \& Juhila, 2021; Tsemberis, 2010) which means that the client's right to the apartment is the top priority, with less obligations regarding clients' cooperation. Tenancy contracts are signed between the client and the municipality's real estate office, who are acting as an intermediary between the tenant and the landlord. Clients within the housing first unit have an opportunity to take over the contract after 18 months. During this time, the real estate office checks that rents are paid, if any disturbances have been reported and makes a final inspection. If tenants do not pay rent, then the 18 months trial period is prolonged. However, more than one missed rent or multiple disturbances can mean that the tenant is evicted. The service targets previously homeless people, most of them having substance abuse and mental health problems.

We included these different contexts because we noticed that despite the different countries, workers in each service spend considerable time just talking about how to engage with their clients in the first place, whether in team meetings or at home visits. Workers often need to motivate the clients and manage cancellations and unrealised visits. The commonness of non-cooperating clients is demonstrated in the data: There were originally 24 observed home visits in Sweden of which eight were cancelled. In the English and Finnish meetings, discussions concerning approximately 20 clients where observed, of which seven English and five Finnish clients were discussed in terms of their non-cooperation. Workers in all services made similar efforts to reach their clients: Travelling to clients' homes without gaining access, rearranging their schedule, trying to reach the client by different means, and negotiating how to proceed amongst themselves and with other professionals. While all three services recognise the challenges to engage all clients, they aim for at least minimal cooperation, such as the client being present at most visits or otherwise easily contactable. Consequently, they must decide if they have tried all available options or when it is not worth proceeding further, in terms of their own time and the consequences for clients of terminating contact.

\section{Data and Analysis}

The data included in this article is chosen from data corpuses collected in the following research projects funded by the Academy of Finland: "Responsibilisation of Service Users and Professionals in Mental Health Practices" (2011-2016) and "Geographies of Home-Based Service Interactions at the Margins of Welfare in Finland and Sweden" (2017-2021). The data consist of:

1. Ten team meetings where floating support workers discuss clients in the current caseload on a 
weekly basis. Five consecutive meetings in the Finnish service were audio-recorded in 2012, and five consecutive meetings in the English service in 2013. Both data sets were collected over approximately two months. Each meeting lasted on average one hour.

2. Four home visits conducted by floating support workers in the Swedish service in 2018. A researcher took notes as she observed the visits on the spot and preparations made before and after the visits. The fieldnotes from four different home visits were collected over the course of four months.

While in team meetings workers discuss unrealised home visits in an institutional meeting gathering without the client present, in field notes the researcher describes the actual, ongoing situation of trying to conduct the visit on the spot, at the client's home (shadowing ethnography; see Lydahl et al., 2020). Consecutive home visits were observed, as well as consecutive team meetings which were recorded, to capture the development of clients' situations and the workers' justifications applied at various stages of the process. In other words, support described in both data sets was analysed as a process.

We started the analysis with team meeting recordings that were transcribed verbatim. All talk on non-cooperating clients was identified, resulting in 23 instances dealing with absences of clients (11 in Finnish and 12 in English data). From these instances we identified one client from both services with particularly persistent 'hard-to-reach' features: They had missed most home visits and demonstrated longstanding absences. As we presented these two client cases from Finland and England in our international research team meeting, we learned that Swedish data, collected for the same research, also included one client that was systematically absent during home visits. This was included as the third case which, by focussing on actual home visits, provides an additional perspective to team meetings where home visits are discussed.

All three hard-to-reach cases that we chose to study in more detail were then scrutinised from the point of view of workers' justifications. We use the term justification to refer to workers' different responses or reactions while accounting for their decisions working with non-cooperating clients. In other words, justifications are workers' ways to argue for progress towards the last resort response, whether that response is the termination of service or introducing more control measures. Besides this common way to use the term, we also draw on Scott and Lyman (1968, p. 51), who point out that when people are justifying their or somebody else's behaviour, they are neutralizing the conduct and its consequences. In other words, justification involves verbal work through which workers can mitigate clients' non-cooperation and support their own procedures. In our view, last resort response is then a par- ticular type of justification. Rys et al. (2013) present a similar understanding of the relation between justifications and last resorts. In their study on physicians' and nurses' moral justifications for using continuous sedation for patients, they find last resort responses to be the most used justification for this extreme medical act (Rys et al., 2013, p. 537).

The three cases were analysed by concentrating on key moments where workers justify the moves towards the last resort response. We found that each client case (while having their own contextual and personal features) was justified by workers in three ways:

1. Failures: pinpointing the failed efforts to reach the client (marked with grey highlight in data extracts). These justifications identify the increasing seriousness of the case with workers talking about the incidents of failing to reach the client and demonstrating a decline in clients' compliance with the rules of the service.

2. Remedial actions: introducing new interventions and allowances to reach the client (marked with orange highlight in data extracts). These justifications range timewise from mild to later stronger actions, offering the client a chance to become a 'remedial client.' The worker proposes new ways of contacting the client and making visits more successful. Remedial actions refer to workers' efforts to overcome the previous failures.

3. Changing characterisation of the client (marked with blue highlight in data extracts). These justifications include the shift from more positive formulations, such as constructing explanations regarding why the client is not present, towards more negative formulations that make particular use of extreme versions of clients' character or their elusive behaviour.

\section{Findings: Justifying the Move to the Last Resort Response}

The findings are reported in three sections, each illustrating a specific process for moving to a last resort-decision: straightforward ending of support (Example 1), gradual ending of support (Example 2), and increased control with continuing support (Example 3). The analytic focus is on how the move to last resorts is justified by workers, both in team meetings (Examples 1 and 2) and home visits (Example 3 ). The examples feature three clientsPauline, Oliver, and Bengt (pseudonyms)-who persistently avoid contact with floating support.

\subsection{Example 1: Straightforward Ending of Support as a Last Resort Response}

Pauline from England receives floating support due to her long-term mental health problems. The service operates under a contract with the municipality. In the 
following team meetings, the workers examine temporally their various failed efforts to reach Pauline, highlighting her non-cooperation:

17 May

Worker 2: Yet again she's not in for a visit, she's not answering her phone, she's not responding to our messages. You tried to get in touch with her.

Worker 3: I phoned [worker from another organisation] yesterday, but I requested that they phone me back and they're sending a message but I haven't looked this morning.

Worker 2: We have seen her out and about in town.

\section{Worker 3: With friends.}

Worker 2: With friends, so we know that she's still in the area. We know that she's alive, we know that she's okay, but she's just not engaging with the service at all.

Workers report futile visits where Pauline has not been at home when visited at appointed times. This has happened repeatedly: "Yet again she's not in for a visit." In addition to presenting the failed visit, the workers summarise the remedial actions they have carried out to reach her: messages and phone calls both to Pauline and her care worker. Workers bring up past occasions where they have seen Pauline in a town with friends. Note the upgrading of the justification from "she's still in the area" to "we know that she's alive." She doesn't seem to be at any particular risk nor difficulty even though she has not used floating support: "We know that she's okay." The workers are reassured they cannot be blamed for abandoning a vulnerable client and can frame her as "just not engaging with the service at all." This characterisation of a clearly disengaged client serves already as the initial move towards the last resort response of terminating the support, even though such a decision has not been made. However, in the next meeting the same failures are brought up again and the same remedial action of calling the other worker repeated:

\section{May}

\section{Worker 1: Pauline, nobody's seen her for weeks.}

Worker 2: Right.

Worker 1: She doesn't answer the door, I tried to ring [worker from another organisation] again yesterday but she wasn't in.

In the next meeting, Worker 1 starts by recapping the futile efforts to reach Pauline "for the last god knows how many weeks." A tone of frustration emerges as the efforts of these pursuits are emphasised:

\section{May}

Worker 1: Pauline, I've tried to contact her for the last god knows how many weeks. I've spoken to [worker from another organisation] who referred her. She hasn't spoke to her either although we have seen her out and about with friends in the town, so we know she's fine, she's just totally disengaged with staff. I phoned her yesterday at two o'clock and left another voicemail message stating that if she didn't contact us before I visit town that her support would be ending, so she didn't ring back so we've now ended support with her.

Worker 2: Do you think it would be worthwhile letting her care coordinator know?

Worker 1: She doesn't have one.

Worker 2: Oh, she doesn't have one.

[Worker 1 starts to talk about another client.]

Three justifications to terminate support are deployed: first, the workers have finally managed to contact Pauline's worker from another organisation, who has also not seen Pauline. Second, the workers repeat the same characterization of someone who apparently is doing well and at no particular risk despite not receiving their support, as workers have seen her "out and about with friends" and they say they "know she's fine." Third, remedial action is carried out which no longer aims at maintaining her support. Instead, she is informed by voicemail of the conditions under which the support will be terminated.

From the workers' point of view, they have now done all the necessary actions and Pauline is framed as having decided herself that she does not need support, since she did not take up the offer to ring back the workers to continue the support. Pauline is now characterised as "totally disengaged with staff," an extreme formulation designating the unavailability of any other means to reach her. The straightforward ending of support is further justified by workers' remedial action to orient to future work that is in line with their ethical responsibility to check the possible collaborators who should know about the termination, in this case, the care coordinator. The fact that "she doesn't have one," can be heard as further justification for termination, since the lack of a care coordinator implies that she does not have serious mental health problems. Also, terminating the support will hold no consequences to Pauline's tenancy.

In summary, the last resort response is justified by retrospective reports that show both Pauline's non-commitment and appropriate professional actions 
carried out to reach her. The last resort response is justified by recapping these retrospective reports several times. Pauline is characterized as independent, clearly making her own choice not to receive support.

\subsection{Example 2: Gradual Ending of Support as a Last Resort Response}

Oliver has severe substance abuse and mental health problems. Unlike Pauline's service above, in the Finnish service the client loses tenancy if floating support is ended. In this sense, ending support has more serious consequences for Oliver. In this example, the last resort response of ending support is constructed more gradually and over a longer timeframe:

\section{October}

Worker: He has been calling [workers] every now and then complaining about his misery and distress. and we have tried to tell him that we do not deal with these things over by the phone and have guided him so that he would be at home at a certain time and we will visit him and then we discuss these issues face-to-face. And, we have agreed a couple of times that he will be there and then we have gone there and the man is not around. And then we have entered the apartment with our own keys and left him a letter, stating that he should contact us so we can talk these things through and discuss what would be the best way for us to support him. Yesterday was the last time we did a home visit with [worker] and we had agreed with him that he would be there and he was not there. But then he called me, turned out he has not been in the apartment at all and had not seen our note we left there. But he called me, at two yesterday afternoon and was drunk so that he must have been at his mates.' but he could clearly talk about things and said he simply cannot stay alone in that apartment and he feels he needs a place with more support.

Oliver is framed as not being totally out-of-reach as he keeps phoning the workers. However, this is not considered the appropriate way to engage with workers from the service's point of view. The primary aim of the service is to carry out home visits and the number of completed home visits will be important when negotiating a new contract with the municipality. As Oliver is not at home as agreed, he is characterised as a client who does not participate the way the service requires. While understanding his distress and characterizing Oliver as somebody who understandably finds it difficult to be at home by himself, the workers still insist on "discussing these issues face-to-face." Next, the remedial action of more serious intervention is reported where workers have used their own key to enter the apartment (unlike in two other services, using the key is allowed). While entering Oliver's empty home, workers leave a letter urging Oliver to contact them. After this yet another futile home visit is described. At this stage Oliver is still characterised as not totally uncooperative: "but he called me." Another excuse is raised in mitigation: Oliver has told workers that "he simply cannot stay alone in that apartment" and "needs a place with more support."

After another three weeks with no successful visit, workers upgrade the seriousness of Oliver's disengagement by planning stronger remedial action, i.e., reporting their difficulties to commissioners. From the team meeting:

\section{October}

Worker: I will raise up Oliver's situation in the commissioners' meeting. It is on Monday so we will hear what they think, but I will tell them what we have discussed here and how things have been progressing and how he is very vaguely committed with this thing. There has been one successful visit and that's that. And there has been promises that he will start coming here [meeting point of the NGO] but there is no sight of him whatsoever.

Oliver's case is shifted to a more formal stage as the commissioners are informed about the problems with home visits to Oliver (except one successful visit). When consulted regarding the future, the commissioners can instruct the service how to react. In the upcoming commissioners' meeting, the worker plans to describe Oliver as "vaguely committed," as someone who makes false promises to cooperate.

In the next team meeting, the commissioners' meeting is not brought up in the team discussion. However, the worker's tone is more frustrated and the plan to end Oliver's support is presented for the first time:

\section{November}

Worker 1: And honestly our understanding is now finishing. As he is in no way collaborating and there has been few times we have reached him by the phone. Well he still drinks. And he has promised to come here to solve this situation but nevertheless has not yet appeared. On Friday we did a spontaneous home visit with [worker] and we let ourselves in with the key as he was not at home and again we left a serious letter on the desk stating that now, now your rental agreement is valid by the end of November. At this point it finishes then, and I hope that he would at least contact us regarding how he will continue.

The formulation of Oliver's disengagement is maintained, even though he is reachable by phone. There have been different strategies of remedial action: phone calls and encouragement in the hope that Oliver will be present 
for a visit. The same remedial action, entering with own key and leaving a letter has now upgraded the seriousness by proposing an imminent ending of the rental agreement. Oliver is now characterised as someone who cannot handle such responsibilities nor can he "at least" let workers know "how he will continue," suggesting an inconsiderate response. Importantly, the last resort response is presented: "At this point it finishes then."

In the next meeting, the characterisation of Oliver changes from partly cooperative to totally uncooperative, further confirming the adoption of the last resort response for ending the support, partly drawing on the commissioners' opinion:

\section{November}

Worker 1: It feels so crazy like you were running after some teenager, trying to chase him all around the world. like you never see him anywhere and cannot talk to him. I dunno this is so weird this running away thing going on with Oliver.

Worker 2: I'm just thinking that should we call his social worker?

Worker 1: Yeah she needs to be notified, where we are with Oliver. But the thing is that he has our apartment and the city is paying for it all the time. [the commissioner] said in our last meeting that this makes no sense, the city won't cover costs for this kind of a guy who doesn't benefit from support in any way and use it. And that is a fact. But the thing is, I wonder can we really, as he is within our support now, well we should anyhow try to consistently guide him towards more supported options. And not act like we will just kick him out in the street.

The emotional tone in which the process with Oliver is described as "crazy" seems to question the legitimacy of the work. Oliver is characterised as a "teenager," with workers trying to "chase him all around the world." The workers' justification is that they have already done everything they can and have acted according to their professional ethics. In the beginning Oliver at least phoned workers, and his absence was partly interpreted as him telling the workers that he cannot cope in the apartment alone. There is a shift to a more extreme formulation of the recurrent impasse: "You never see him anywhere." Responding to the commissioners' opinion, the support is finally terminated, characterizing Oliver as "a guy who doesn't benefit from support in any way."

In summary, after the decision to terminate, the workers recognise their responsibility to guide Oliver towards a different placement with "more supported options." Support is ended progressively and ethically by planning Oliver's future in collaboration with other actors and seeking a more appropriate service for him.

\subsection{Example 3: Increased Control with Continuing Support as a Last Resort Response}

The final case is located in Sweden and presents Bengt, who is a client of the municipality's Housing First programme due to his previous homelessness. He receives floating support from the team. This example is different from the previous ones as the last response does not include plans to terminate Bengt's support at any phase. Instead, workers continue support by increasing control and mitigating his absence, while still drawing on similar justifications to previous last resort responses utilising failed attempts and remedial actions. The first observed home visit starts with workers entering Bengt's apartment:

24 May

We go to Bengt's house and enter the front door and call on Bengt's door but get no response. Marita tries several times. Jonas takes out a card in hardcover in A5 where the Housing Organization and the Administration for allocation of social welfare's logo is printed. He writes the following on the card "Hi! We have tried to reach you and it was a long time since we heard of you. Call us! With kind regards. Jonas tries to put the card in the mailbox, but it is glued shut. Marita says that it is common with their clients. However, Bengt has a mailbox in the stairwell, so we put the card there instead. When we go out, Jonas asks, "is it us he avoids?" Marita replies that it may be "he's in a period [of drug/alcohol use] and I think he's stuck in the old and thinks he's going to get lectured.

After Bengt fails to answer his door, the remedial action of leaving him a note is carried out. The card kindly says that workers have tried to reach him and urges Bengt to phone them. The mailbox is glued shut which strengthens Bengt's characterisation as someone "hardto-reach": He is not physically present and cannot easily be approached by post either. Explanation and normalisation for this behaviour is provided by the worker: "It is common with their clients." The workers seek reasons for Bengt's avoidance by characterising him as someone who has possibly started using drugs again. Importantly they do not say that they will lecture Bengt, but rather that Bengt thinks that he is going to "get lectured." Being "stuck in the old," in this context refers to the idea that Bengt thinks he will be reprimanded for using drugs again, which he will not, the workers later explained. As part of the Housing First programme, the workers subscribe to a harm reduction approach, in which using drugs is not a cause for eviction nor sanction.

The workers make another unannounced home visit, observed by the researcher, but again no answer. However, they noted an open balcony door with a light in the bathroom, implying that somebody might have been 
at home, but the workers were not let in. Before the next visit observed by the researcher, the worker informs her colleagues about Bengt's situation:

\section{June}

Marita says that they did not get hold of him for a long time and when they last entered the apartment they did not even meet Bengt. Instead, someone who claimed to be Bengt's friend opened and said that Bengt was asleep. Marita says she thinks that they should leave a note to Bengt saying they are worried and will contact the police if Bengt does not get in touch with them. The other workers agree that sounds like a good idea. "What do we write on this piece of paper," Marita wonders. Eva, her colleague, asks "Has anyone taken over his apartment?" Elin and Boel, other colleagues, say almost at the same time that they have also had that thought. Elin says that Marita can try to write something about supporting Bengt with the rent. Apparently, Bengt has failed to pay 3 rents and there is now a risk that he will be evicted if he does not pay. Eva says that they should write "we are worried about you. If we do not hear from you then we'll enter the apartment with the police. "If someone has taken over the apartment, it might be easier to get them out if one says that the police will come, says Elin.

The previous failed efforts to visit Bengt are reported: As before, the workers have not "get hold of him for a long time." However, a new kind of problem is reported where, during the last home visit, someone else had opened the door. As the workers suspect that this person might have "taken over his apartment," a significant increase of control supersedes the previous remedial action of merely leaving a note. The current note includes more serious threats and concerns. First, the workers propose stronger control, as they inform Bengt (or somebody living in the apartment) that they plan to involve the police, to secure Bengt's apartment from others who might have taken it over. Second, the note highlights the problem of rent arrears, suggesting Bengt could be supported with the rent. While not explicit in the note, a possible eviction is implied. Bengt is now characterised as an upgraded risk if he loses his tenancy contract. Although eviction does not mean terminating support (unlike with Pauline and Oliver), it would create extra problems to address. The workers would have to participate in negotiating a new tenancy for Bengt, as well as finding ways of supporting him to keep the new contract. Furthermore, Bengt is characterised as vulnerable to others taking advantage of his apartment.

A few months later, when workers again are observed by the researcher, they succeed in visiting Bengt. This extract lacks the different justifications to move towards the last resort response, because the last resort response has already taken place in the form of increased control when workers suggested to involve the police to get access to Bengt's home:

\section{September}

We still go to the outer door, Marita is calling, and he opens. We walk halfway up to his apartment door. He stands in the door and Marita presents me- "This is [researcher], can she come in? She will study how I work." It's fine, Bengt says, and we go in [descriptions of the home]. Bengt has produced three coffee cups. Me and Marita sit down on each side of the kitchen table. Bengt sits on the short side after he poured coffee for us and presented a packet of vanilla cookies. Marita and I tell him about my study, and Marita stresses that it is voluntary to participate and if he should regret it, he can also say afterwards that he does not want to participate. Bengt has no problems with participating he says and I give him the written information and asks if it might be okay for me to record the conversation between Marita and him. It is.

Finally, Bengt opens the door and a home visit is conducted that can be interpreted as successful. Bengt acts like a welcoming host, by offering the worker and researcher coffee and biscuits, and by informing them of his willingness to take part in the research. Support provided to Bengt during the home visit is successful, as seen by the way the visit continues after this extract: the research describes Bengt and Marita as starting to sort out the rent and having a shared plan to manage payments.

In summary, throughout the process, the workers did not withdraw the support at any point, although it was seen as an (unpreferred) option. Instead, the last resort response was an increase in control and insistence to secure the apartment for Bengt. Control was used to re-establish the service, not to end it. In this respect, Bengt's example contrasts with those above, as support continues, and the last resort response uses stronger measures: highlighting possible eviction and plans to invite the police to inspect the apartment. There is a fine line between stronger remedial actions and what constitutes as last resort response. Furthermore, the characterisation of Bengt remains more positive than in two previous cases.

\section{Conclusion}

We have studied floating support workers' efforts to reach clients who are persistently absent when the worker makes a home visit. Analysing the workers' efforts to re-engage with these clients, we identified three types of justification the workers use for last resort responses to terminate support or, alternatively, increase control and insistence: First, retrospective sum- 
maries on past failures to reach the client; second, intensifying remedial actions to engage with them (unannounced visits, phone calls, leaving notes, entering the apartment and consulting other professionals); and third, characterisations of clients as uncooperative. Once remedial actions have repeatedly failed, the decisionmaking containing the last resort response is invoked.

As we studied team meetings and home visits conducted by a group of workers, the justifications draw to some extent on shared notions of the ethics, values and working practices of the services (Saario et al., 2018). However, the ethical implications vary considerably between each example, especially concerning the termination of support. Pauline's case (the first example) demonstrates how the service was ended with little scrutiny. Pauline apparently showed little motivation and seemingly was not at increased risk without the visits. Furthermore, the service did not hold wider responsibilities for Pauline's ongoing care, nor did they need to justify termination to other agencies. Ending the service was more complicated in Oliver's case (the second example), as he was seen by workers as needing extra support, with which he concurred. The service was committed to engage with Oliver and, after the termination, still participated in planning his future. In both cases the workers, in consultation with their colleagues, actively constructed the last resort responses. In contrast, in Bengt's case (the third example) support was not ended but increasingly controlling measures were carried out due to outside circumstances (possible intruders at his home and rent arrears). Stronger measures were proposed while not withdrawing the case but carrying on until Bengt was reached again.

Furthermore, the different last resort responses can be viewed from the point of view of workers' relation to the autonomy of clients (Lydahl \& Hansen Löfstrand, 2020). It could be that the service is terminated in Pauline's and Oliver's cases, as there is respect for clients' making their own choice of not opening the door and having workers visiting them, whereas the workers continued to pursue Bengt even after several absences on his part. Perhaps, also the looser ongoing responsibilities in the contract between clients and the workers in the first two services seem to suggest that they engage in less remedial work. Such dilemmas can be mapped in terms of a continuum between promoting client autonomy and choice versus control and insistence. The services examined here are near the client autonomy end of the continuum. In contrast Brodwin (2013, p. 64) examines assertive community treatment teams in the US, where the worker cannot end involvement with the client and where compliance (especially with medication) is the central concern. He discusses criticisms of such services as coercive, "overt paternalism" (Brodwin, 2013, p. 181), contrasted with "developing long term relationships oriented around clients' own goals" (p. 184). Both extremes of abandoning the uncooperative client and imposing treatment are last resort responses.
We suggest that processes towards last resort responses are important to study because they are essential features of organisational interactions in which formulations of clients are constructed. Besides home visiting programmes, engaging hard-to-reach clients is an issue in many social care services. Furthermore, being hard-to-reach is considered a risk especially for the most vulnerable clients, such as the clients studied in this article. While our data do not show the consequences of non-cooperation from clients' own perspective, severe consequences are reported by earlier research including evictions, increased homelessness, self-harm and suicide (e.g., Doherty et al., 2003; Maeseele et al., 2013; Stenius-Ayoade, 2019).

This article illustrates a variety of workers' efforts to deal with clients' non-cooperation by applying Emerson's idea of 'the last resort' in everyday interaction of social care work. While we demonstrated different ways individual workers respond to clients with whom it is difficult to maintain contact, more research is needed to clarify the process of decision-making concerning the ending of support. Especially different service models and their contractual practices may have a significant role in decision-making concerning non-cooperating clients. This calls for paying attention to the different processes that precede workers' last resort responses, as well as recognising the organisational procedures and services that build on the logic of last resort.

\section{Acknowledgments}

This article is based on two international research projects funded by the Academy of Finland: "Responsibilisation of Service Users and Professionals in Mental Health Practices" (2011-2016) and "Geographies of Home-based Service Interactions at the Margins of Welfare in Finland and Sweden" (2017-2021).

\section{Conflict of Interests}

The authors declare no conflict of interests.

\section{References}

Andersson, B. (2013). Finding ways to the hard to reach. Considerations on the content and concept of outreach work. European Journal of Social Work, 16(2), 171-186.

Beresford, P. (2005). 'Service user': Regressive or liberatory terminology? Disability \& Society, 20(4), 469-477.

Brodwin, P. (2013). Everyday ethics: Voices from the frontline of community psychiatry. University of California Press.

Cortis, N. (2012). Overlooked and under-served? Promoting service use and engagement among 'hard-to-reach' populations. International Journal of Social Welfare, 21(4), 351-360. 
Doherty, P., Hall, M., \& Kinder, K. (2003). On track thematic report: Assessment, referral and hard-to-reach groups (Research Report 475). National Foundation for Educational Research. https://www.education. gov.uk/publications/eOrderingDownload/RR475.pdf

Froonjian, J., \& Garnett, J. L. (2013). Reaching the hard to reach: Drawing lessons from research and practice. International Journal of Public Administration, 36(12), 831-839.

Grymonprez, H., Roose, R., \& Roets, G. (2017). Outreach social work: From managing access to practices of accessibility. European Journal of Social Work, 20(4), 461-471.

Hansen Löfstrand, C., \& Juhila, K. (2021). Transforming worker-client identities: From shelters to Housing First. Social Inclusion, 9(3), 214-222.

Harnett, T., \& Jönson, H. (2020). 'Wet' eldercare facilities: Three strategies on the use of alcohol and illicit substances. Nordic Social Work Research. https://doi. org/10.1080/2156857X.2020.1742195

Heimer, C., \& Staffen, L. (1995). Interdependence and reintegrative social control: Labeling and reforming "inappropriate" parents in neonatal intensive care units. American Sociological Review, 60(5), 635-654.

Hjörne, E., Juhila, K., \& van Nijnatten, C. (2010). Negotiating dilemmas in the practices of street-level welfare work. International Journal of Social Welfare, 19(3), 303-309.

Emmel, N., Hughes, K., Greenhalgh, J., \& Sales, A. (2007). Accessing socially excluded people: Trust and the gatekeeper in the researcher-participant relationship. Sociological Research Online, 12(2). http:// www.socresonline.org.uk/12/2/emmel.html

Emerson, R. (1981). On last resorts. American Journal of Sociology, 87(1), 1-22.

Juhila, K., Hansen Löfstrand, C., \& Raitakari, S. (2021). Devoted work without limits? Activities and premises of home visit work at the margins of community care. International Journal of Care and Caring, 5(2), 247-262.

Järvinen, M., \& Miller, G. (2010). Methadone mainte- nance as last resort: A social phenomenology of a drug policy. Sociological Forum, 25(4), 804-823.

Lindenberg, R. E. (1958). Hard to reach: Client or casework agency? Social Work, 3(4), 23-29.

Lydahl, D., \& Hansen Löfstrand, C. (2020). Doing good: Autonomy in the margins of welfare. Sociology of Health \& Illness, 42(4), 892-906.

Lydahl, D., Holmberg, S., Günther, K., \& Ranta, J. (2020). Doing data together-Affective relations and mobile ethnography in home visits. Qualitative Research. Advance online publication. https://doi. org/10.1177\%2F1468794120917913

Maeseele, T., Bouverne-De Bie, M., \& Roose, R. (2013). On the frontline or on the side-line? Homelessness care and care avoiders. European Journal of Social Work, 16(5), 620-634.

Miller, G., \& Holstein, J. (1995). Dispute domains: Organizational contexts and dispute processing. The Sociological Quarterly, 36(1), 37-59.

Rys, S., Mortier, F., Deliens, L., Deschepper, R., Pabst Battin, M., \& Bilsen, J. (2013). Continuous sedation until death: Moral justifications of physicians and nursesA content analysis of opinion pieces. Medical Health Care and Philosophy, 16(3), 533-542.

Saario, S., Räsänen, J.-M., Raitakari, S., Banks, S., \& Juhila, K. (2018). Doing 'ethics work' together: Negotiating service users' independence in community mental health meetings. Ethics and Social Welfare, 12(4), 370-386.

Scott, M., \& Lyman, S. (1968). Accounts. American Sociological Review, 33(1), 46-62.

Stenius-Ayoade, A. (2019). Housing, health and service use of the homeless in Helsinki, Finland [Unpublished doctoral dissertation]. University of Helsinki. https:// helda.helsinki.fi/handle/10138/301731

Tinker, K. (1959). Casework with hard-to-reach families. American Journal of Orthopsychiatry, 29(1), 165-171.

Tsemberis, S. (2010). Housing First: The pathways model to end homelessness for people with mental illness and addiction. Hazelden Publishing.

\section{About the Authors}

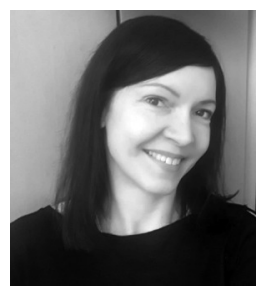

Sirpa Saario holds a PhD in Social Sciences and works as a University Lecturer in social work at the Faculty of Social Sciences, Tampere University. Her research interests include boundaries and technologies in health and social care, transformation of expertise among welfare professions, as well as the connections between professional accountability and new public management. She has published in journals such as Social Science \& Medicine, Sociology of Health and IIIness, Ethics \& Social Welfare, and Journal of Technology in Human Services.

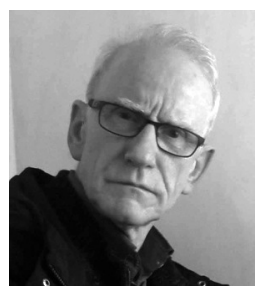

Christopher Hall is Visiting Senior Research Fellow at the Department of Social Work and Social Care, Sussex University, having held research posts at Durham, Huddersfield, and Bristol Universities. His research examines policy and practices in child welfare and mental health, especially professionalclient interaction. He is currently engaged in research on home visits in social work and social care. 
Doris Lydahl holds a PhD in Sociology and is a Researcher at the Department of Sociology and Work Science, University of Gothenburg. In her research she focuses on everyday life and routine work as important locations where politics, science and technology meet and enact their normativities. She currently leads a project about the values of welfare technologies in elderly care. She has published work in journals such as Health, Sociology of Health and IIIness, and Qualitative Research. 